\title{
THE RELATIONSHIP BETWEEN ORGANIZATIONAL CULTURE AND KNOWLEDGE MANAGEMENT COMPONENTS OF LAWSON
}

\author{
Farah Shahraki Sanavi \\ MA in Educational Management, Alzahra Eye Hospital, Zahedan Medical Sciences University
}

Fatematolsadat Robati

$\mathrm{PhD}$ in Curriculum, Department of Management, Faculty of Literature and Human Sciences, Islamic Azad

University of Kerman

Farideh Shahraki Sanavi

Bachelor in Public Management, Authority and Jobs Office, Ports and Shipping Organization of Tehran

\begin{abstract}
This study aimed to investigate the relationship between organizational culture and its relation with knowledge management. This is a correlational study and its statistical population consisted of all nurses working in hospitals of Zahedan Medical Sciences University. The sample size by using Morgan table was 250 persons that were selected by stratified random sampling method in proportion to population size within classes. The instrument used in this study was a questionnaire containing 60 questions of Denison organizational culture questionnaire (2000) with a reliability of 0.90 and 24 questions of questionnaire of Knowledge Management Lawson (2003) with reliability of 0.89 . Information obtained by using descriptive and analytical statistics (Spearman correlation coefficient and linear regression) and SPSS15 software was analyzed. The study results showed that there is statistically significant relation $(p<0.01)$ between organizational culture of studied individuals and all the knowledge management components. Also, the Linear regression analysis results showed that components of knowledge organizing and knowledge application were predictive of organizational culture in the model. Totally, KM initiatives were $26 \%$ predictor of organizational culture. According to the correlation between structural and cultural factors of organization and knowledge management as well as the role of knowledge in the quality of medical services provided by the centers, it is recommended to pay necessary and comprehensive attention to the structural and cultural dimensions of organization in the implementation of knowledge management in healthcare centers.
\end{abstract}

Keywords: knowledge management, organizational culture, Lawson, nurse

\section{INTRODUCTION}

Many experts consider today's world as the era of discontinuity which means that the past experiences and solutions are not suitable for current issues and the future of organizations and we should think in a different way and look for new organizational solutions with the new structure (Nasrollahi). In recent years, various organizations and companies have begun to join the process of knowledge and new concepts such as knowledge work, knowledge of work, knowledge management and organization of knowledge inform about the intensification of this process. Draker by using this terminologies announces the creation of a new type of organization in which instead of arm strength, power of the mind is the rule. According to this theory, in the future societies can be expected to be developed and advanced that have more knowledge (Alvani). Although, corporate culture has a long history, it is an issue that is recently proposed in knowledge management especially in the realm of organizational development and organizational behavior (Shojaeei, Zivaryar, Gholamalizadeh, Esmaeeli Bid Hendi, 2005). However, many published studies and articles point to the key influence of organizational culture on knowledge management or knowledge sharing effectiveness (Gold, Malhotra. Segars, 2001; Yeh, Lay, Ho, 2006). Organizational culture is a combination of values, beliefs, behavioral models and symbols. Organizational culture reflects the organization's value system and can be regarded as behavioral norms of employees. 
Therefore, in general, organizational culture is a set and system of common understanding that members have towards the organization, and this feature led to the separation of two organizations. Culture not only determines the value of the knowledge and explains the advantage of knowledge creation for the organization (Park, Ribiere, Schulter, 2004), but also it influences the efforts of staff that take place with their satisfaction and desire to share knowledge. Then it should be said that organizational culture can be one of the factors in the success or failure of organizations in today's dynamic and changing environment (Shojaeei, Zivaryar, Gholamalizadeh, Esmaeeli Bid Hendi, 2005). Therefore, being able to create a culture in which the access to knowledge is easy for managers during the implementation of knowledge management is essential.

Davenport said that eight factors contribute to the success of knowledge management projects and a number of them were associated with the corporate culture. His research showed that even when an organization has a complete system of knowledge management, the lack of supportive organizational culture causes the performance of knowledge management to be limited in that organization and only in the case of existence of both knowledge management and organizational culture the work of organization will reach its maximum (Davenport, Grover, 2001). Alavi and Leidner (2001) in their study reached the conclusion that the success of knowledge management is closely related to culture. Therefore, from their perspective the success of knowledge management depends on culture, management and cooperation of different levels of organization (Alavi and Leidner, 2006). On the other hand, many researchers including Delong and Fahey (2000) in their research showed a high percentage of organizations that deal with knowledge management strategy and have not achieved their goal. They introduced organizational culture as the main obstacle in the creation and application of knowledge capitals. They also noted that knowledge rather than an asset is a process and in order to maximize its worth, an organization needs to create an environment which contributes the knowledge flow. They after experimental studies of this research also found that an organization for effective use of knowledge management should provide mutual trust culture for employees and maintain a level of confidence (Delong W. Fahey, 2000). The results of studies indicate the extent and importance of the role of culture in knowledge management, the impact of knowledge management success in support of culture, the necessity to identify suitable individual and organizational behaviors to the successful implementation of knowledge management, the direct role of organizational culture type in the successful dissemination of knowledge management systems and the possibility of increasing the effectiveness of the implementation of knowledge management in organizations due to the nature and characteristics of the organizational culture. One of the most important aspects of any knowledge management system is the culture changing discussion therefore, the study of the relationship between organizational culture and its impact on the implementation of knowledge management is essential. On the other hand, it should be noted that different institutions and departments have different organizational cultures. Definitely, the culture of a private organization is different from the culture of public organization. Therefore, it is necessary to investigate this relationship in health care organizations such as hospitals because different cultures can influence various factors in organizations such as job satisfaction, people's creativity, production, sharing and application of knowledge management and so on. Thus, this study aimed to examine the relationship between knowledge management and its components with the corporate culture among employees of Zahedan Medical Sciences University and specify the relationship between these two indices. Since the major objectives of Zahedan Medical Sciences University are to create wide developments at the hospitals covered by this University. The results could pave the way for implementation and improvement of supper-oriented techniques and organizational improvement of hospitals and their performance. Also, managers by being aware of organizational culture of hospital can attempt to fix possible defects and prepare hospital for successful improvement and transformation.

\section{MATERIALS AND METHODS}

This is an applied (descriptive-survey) study that is done on the medical staff working in hospitals of Zahedan Medical Sciences University. According to the statistics department of Medical Sciences University of Zahedan in 2015 the total number of nurses employed in hospitals affiliated with this University were 688 subjects that based on Morgan table the sample size was 248 subjects that were selected by stratified simple sampling method in proportion to population size within classes in hospitals of Zahedan Medical Sciences University so that according to the total number of nurses working in each hospital, the sample size in each hospital was specified and ultimately 250 people were examined. Two questionnaires of Denison 
Organizational Culture (2000) and Sharon Lawson knowledge management (2003) were used to collect data. The standard questionnaire of organizational culture made by Denison (2000) including indicators of participatory culture, stability-based culture, flexibility culture and mission culture investigated the dimensions of stability, flexibility, internal focus and external focus in the organization. The questionnaire includes 60 items that was valued with Likert 5 options (Numbers from 1 to 5). Its validity by using experts' ideas and its reliability by using Cronbach's alpha (0.93) was calculated and verified. Also, knowledge management questionnaire of Sharon Lawson (2003) was used to examine the elements of creation, attrition, organizing, storage, dissemination and application of knowledge. Each component is made up of four items. Totally, the questionnaire consisted of 24 items that was measured with Likert scale of 5 options (Numbers from 1 to 5). The obtained information was analyzed by using descriptive statistics (frequency, percentage, mean score and standard deviation) and analytical (Spearman correlation coefficient and linear regression) and software SPSS15.

\section{FINDINGS}

The present study was done on 250 nurses working in the hospitals of Medical Sciences University of Zahedan. Nurses participating in the study, $0.86 \%$ was male and $0.14 \%$ was female. The majority of them namely, $82.8 \%$ were under 40 years old and $66.2 \%$ of them had less than ten years work experience.

The average score obtained for organizational culture was1/35 $\pm 7 / 89$ and its components have had a similar average score. The total score of knowledge management was assessed $15.4 \pm 62.0$ and mean score of subscale of knowledge management includes knowledge creation, knowledge capture, knowledge organizing, knowledge storage, knowledge dissemination and knowledge application 10.4, 10.2, 10.7, 9.8, 10.3 and 10.4 respectively.

Table 1. Spearman correlation coefficient between organizational culture and components of knowledge management of studied subjects

\begin{tabular}{|ll|l|l|l|l|l|}
\hline $\begin{array}{l}\text { Components of } \\
\text { knpwledge } \\
\text { management }\end{array}$ & $\begin{array}{l}\text { knowledge } \\
\text { creation }\end{array}$ & $\begin{array}{l}\text { knowledge } \\
\text { capture }\end{array}$ & $\begin{array}{l}\text { knowledge } \\
\text { organizing }\end{array}$ & $\begin{array}{l}\text { knowledge } \\
\text { storage }\end{array}$ & $\begin{array}{l}\text { knowledge } \\
\text { dissemination }\end{array}$ & $\begin{array}{l}\text { knowledge } \\
\text { application }\end{array}$ \\
$\begin{array}{l}\text { Organizationat } \\
\text { culture }\end{array}$ & 0.38 & 0.41 & 0.45 & 0.41 & 0.41 & 0.47 \\
\hline $\begin{array}{l}\text { Correlation } \\
\text { coefficient }\end{array}$ & \multirow{2}{*}{0.0 .01} & & & \\
\hline
\end{tabular}

The results of Table 1 indicates the moderate positive correlation between organizational culture and components of knowledge management in studied nurses.

Table 2. Results of multiple regression analysis of organizational culture and knowledge management components with input method

\begin{tabular}{|l|c|c|c|c|c}
\hline \multicolumn{1}{c|}{$\begin{array}{c}\text { Sources of } \\
\text { change }\end{array}$} & $\begin{array}{c}\text { Sum of } \\
\text { squares }\end{array}$ & Degrees of freedom & Mean Square & \multirow{2}{*}{ F ratio } & Significance \\
\hline Regression & 42.82606 & 6 & 73.13767 & 14.90 & 0.001 \\
\cline { 1 - 4 } Remaining & 17.224467 & 243 & 73.923 & & \\
\hline
\end{tabular}


Total

60.307073

249

The information provided in Table 2 indicates that the effect of regression $(\mathrm{F}=14.90)$ caused by knowledge management components is statistically significant. According to the results obtained in the above table it can be stated that the predictive ability of organizational culture of studied nurses is through their knowledge management components. Hence, components of knowledge management are eligible to predict organizational culture $(\mathrm{p}<0.001)$.

Table 3. Results of predicting organizational culture based on knowledge management components

\begin{tabular}{|c|c|c|c|c|c|}
\hline \multirow{2}{*}{ Statistical Indicators } & \multirow{2}{*}{$\begin{array}{l}\begin{array}{l}\text { Non- } \\
\text { standardized } \\
\text { coefficients }\end{array} \\
\text { Beta }\end{array}$} & \multicolumn{2}{|c|}{ standardized coefficients } & \multirow{2}{*}{ T Ratio } & \multirow{2}{*}{$\begin{array}{r}\text { Significance } \\
\text { level }\end{array}$} \\
\hline & & standard error & B & & \\
\hline Constant coefficient & 120.41 & 8.16 & - & 14.75 & 0.001 \\
\hline knowledge creation & 0.53 & 0.99 & 0.04 & 0.53 & 0.59 \\
\hline knowledge capture & 1.06 & 1.17 & 0.09 & 0.90 & 0.36 \\
\hline knowledge organizing & 2.73 & 1.21 & 0.23 & 0.24 & 0.02 \\
\hline knowledge storage & 0.94 & 1.16 & 0.07 & 0.80 & 0.42 \\
\hline knowledge dissemination & 0.31 & 1.08 & 0.02 & 0.28 & 0.77 \\
\hline knowledge application & 2.84 & 0.97 & 0.26 & 2.91 & 0.004 \\
\hline
\end{tabular}

There is a significant correlation $(\mathrm{P}<0.001)$ between components of knowledge management and organizational culture among nurses working in Zahedan Medical Sciences University and elements of knowledge organizing and knowledge application were significant predictors in this model (Table 3). Totally, components of knowledge management about $26 \%$ was predictor of organizational culture.

\section{DISCUSSION}

To identify the organization and investigate the behavior and performance of members of an organization, awareness of organizational culture is an important and fundamental step. Thus, to do any new action in organization, paying attention to culture of that organization is essential because by leverage of culture the variation can be implemented simply and new directions can be sustainable in the organization. In fact, any change in the organization will not be effective without sufficient attention to corporate culture. Also, if managers are seeking to increase productivity and organizational performance, they should consider the constituent elements of corporate culture. The results of the study of organizational culture among nursing staff of hospitals of Zahedan Medical Sciences University indicate the relative balance of their evaluated score in all dimensions that based on Denison model due to the inherent contradictions among various aspects of culture, the best possible situation for an organization is the balanced growth of various dimensions in it. A healthy organizational culture provides an open, sincere, confident, creative, 
collaborative, experimental, scientific, rational, logical environment in the liberation of abilities of individuals and potential of the organization (Gorden, 2005).

Also, the mean score of knowledge management of nurses in the hospitals of Zahedan Medical Sciences University was less than average. The study results of Ameri (Seydameri, 2008) and Karami (2005) in the center of the Bahman Khodro also indicated that the knowledge management was in moderate state or lower than it. In line with these studies, Moghadam Zanjani has stated that knowledge management is weak in Medical Sciences University of Zanjan. In studied hospitals, $65.5 \%$ of the staff have evaluated knowledge management weak, 43\% average and only 5\% strong (Valimoghadam Zanjani, 2008).

Knowledge management has many benefits for organizations. Knowledge management at individual level will allow staff to enhance their skills and experience by working with others and sharing in their knowledge and learning to achieve professional growth. At the organizational level, knowledge management has four major advantages for an organization. Improving organizational performance is through efficiency, productivity, quality and innovation thus, organizations consider knowledge management as a strategic and competitive advantage (Seifollahi, Davari, 2008). Knowledge management helps organizations deal with changes continuously through learning and renewal of knowledge (Rading Allen, 2004). In line with knowledge management implementation three key issues have raised which including the formulation of strategic plans based on knowledge, forming knowledge groups, and reward-based reward and wage system (Tat, Stewart, 2007). Although accessing to knowledge-based organization is difficult, organizations should plan to improve and implement knowledge management. The findings indicated a positive relationship between organizational culture and components of knowledge management. Multiple regression analysis showed that factors of knowledge organizing and knowledge application were predictor of organizational culture. In this regard, Rai (2011) in his study stated that since the hierarchical culture leads to the improvement of procedures and processes of the system, it entails the rainforcement of organizing processes and knowledge storing which have beneficial effects on knowledge management (Rai, 2011).

Also, De Long and Fahey (2000) in his research reported that in order to the knowledge management to be successful in an organization the existence of a competitive culture that motivates employees and gives positive feedback is necessary which in their own turn resulted in the development and circulation of knowledge in the organization. Also showed that timely support, reward and encouragement of people plays an important role in the relationship between people and knowledge of organization (Delong, Fahey, 2000).

Jafari and colleagues (2012), in their study investigated the relationship between organizational culture and knowledge management among teachers in Ahvaz city and concluded that there is a significant and positive relationship between organizational culture and all its seven factors (competition, social responsibility, supportiveness, innovation, emphasis on reward, performance orientation, stability) with knowledge management. Also, the regression results revealed that all seven components of organizational culture can predict knowledge management that its $\mathrm{R}$-squared value was 0.71 and this means that predictor variable (organizational culture) can predict $71 \%$ of the changes in knowledge management. $\beta$ coefficient also showed that competition component has the most power to predict the knowledge management (Jafary, Abbaspour, Azizishomami, 2013). Perrin (2005) in a study entitled "the analysis of the usefulness of integrated knowledge to manage the organizations" came to the conclusion that the most effective tool for knowledge exchange and sharing among staff of organization refers to the use of email, Internet, and corporate culture along with knowledge management that due to the improper and untimely use of this tool, knowledge is exchanged among employees of economic institutions with delay and individuals' needs cannot be met on time in terms of working knowledge (Perrin, 2005).

An organization should identify, acquire and storage its required knowledge in order to be able to apply it in necessary situations. Knowledge Management includes the processes of knowledge creation, knowledge validating and knowledge forming, knowledge distribution and its scientific application in the organization. Actually, the ultimate goal of knowledge management is the application of knowledge to improve organizational performance. Knowledge in itself is not valuable, but it is valuable when it is used (Shami Zanjani, 2009). Knowledge management aims to ensure that whether the knowledge of the organization is used for its benefit or not (Martin, 2011). 
Martin (2011) conducted a study entitled investigating the relationship between organizational culture and knowledge management in eight different organizations of America. His study results showed that organizational culture is positively related to knowledge management. He also concluded organizations that enjoy relative stability and support people in difficult situations cause the people to be more interested in learning, creating and developing knowledge (Martin, 2011). With regard to what has been mentioned the most important thing is that due to the low level of familiarity and applying the principles of knowledge management in health and treatment organizations, administrators should plan in this regard. Accordingly, Elsey \& Eskandari said that, health and treatment plans are directly guided by knowledge. These two researchers in their study results emphasized on the need of senior managers in knowledge acquisition and modernization of education in teaching hospitals of Iran (Elsey, 1999). Therefore, according to the results of this study and previous studies, health care organizations can make knowledge applicable by using and dissemination of corporate culture and employee participation.

\section{CONCLUSION}

As the results showed, knowledge management and corporate culture are associated with each other. Managers with a focus on organizational culture can play a role in improving knowledge management and vice versa. According to the regression test results, it is proposed to emphasize on the knowledge dissemination or sharing to develop organizational culture among the studied population and this is achieved through establishing trust atmosphere in the organization so that employees do not feel danger from the professional knowledge transfer to other people, encouraging knowledge-oriented individuals to transfer knowledge to other people and define a process by which competitors' knowledge to be exploited. Encourage employees to exchange knowledge and experiences with each other, forming group sessions to exchange ideas, creating a friendly and reliable atmosphere among employees, preparing bulletins and group discussion to decide in certain cases, increasing interaction between officials and staff, facilitating the access of employees to information related to their work, and increasing the interactions among employees that their work is linked together are considered to enhance knowledge management in the research population.

Any conflict of interest has not been expressed by the authors.

\section{APPRECIATION}

It is necessary to appreciate the nursing staff of Medical Sciences University of Zahedan who helped us in the accomplishment of this study. This study is derived from the MA thesis of Educational Administration of Islamic Azad University of Kerman.

\section{REFERENCES}

Nasrollahi M. The impact of knowledge management on entrepreneurship and innovation in the province of Sport and Youth staff. Master thesis. Faculty of Physical Education and Sport Sciences, Ahvaz University of Shahid Chamran.[Persian]

Alvani SM, Danaei Fard H. Speeches on philosophy, theory of government agencies. First Edition. Saffar publications.[Persian]

Shojaeei M, Zivaryar F, Gholamalizadeh R, Esmaeeli Bid Hendi H. Assess and explanation of the organizational culture of technical faculty of Pardis Tehran University. Quarterly of Management Culture2005; 3(11): 5-17.[Persian]

Gold A H, Malhotra A. Segars A H. Knowledge Management: an Organizational Capabilities Perspective. Journal of Management Information Systems 2001; 18(1): 185 - 214.

Yeh Y J, Lay S Q, Ho C T. Knowledge Management Enablers:A Case Study. Industrial Management \&Data Systems 2006; 106(6): 793-810.

Park H, Ribiere, Schulter W D. Critical attributes of organizational culture that promote knowledge management technology implementation succer. Journal if Management 2004; 8(3): $106-107$.

Davenport T, Grover V. Knowledge management. Journal of Management Information Systems 2001; 18(1): 3-4. 
Alavi M, Leidner DE. The Role of Culture in Knowledge Management: A Case study of Two Global Firms. International Journal of Collaboration 2006; 2(1): 17- 40.

Delong W. Fahey L. 2000. Diagnostic culture Barriers to knowledge management The Academy of Management Executive, 14(4): 113 - 127.

Gorden P. organizational culture. Journal of organizational Knowledge Management 2005; 9: 13-15.

Seydameri H. Relationship between organizational factors and knowledge management. Journal of research in sport science 2008: 20. [Persian]

Karami M. Relationship between organizational culture and knowledge management in Bahman Industrial Group. Master thesis. Tehran University. 2005. [Persian]

Valimoghadam Zanjani S. The Relation between Organizational Culture and Knowledge Management in educational curative Centers of Zanjan University of Medical Sciences. Master thesis. Tehran: School of Management and Economy, Science and Research Branch Islamic Azad University 2008.[Persian].

Seifollahi, N., Davari, M.R. (2008). Knowledge management in organizations, Tehran: Book Publication of Arad. S38-36

Rading Allen. (2004). knowledge management, Trans: Latifi, M.H., Tehran: SAMT Publication, 178.

Tat L.W, Stewart H. Knowledge Management in the Malaysian Aerospace Industry. Journal of Knowledge Management 2007; 11( 1):119.

Rai R K. Knowledge Management and Organizational Culture: a Theoretical Integrative Framework. Journal of Knowledge Management 2011; 15(5): 779- 801.

Jafary S, Abbaspour A, Azizishomami M. The effect of organizational culture on the knowledge management implementation processes from the viewpoint of Education Dept employees. Interdisciplinary Journal of Contemporary Research in Business 2013; 5: 237- 245.

Perrin T C. An analysis of knowledge integrator effectiveness in managing organizational knowledge. School: Capella University. 2005.

Anvari, A.A., Shahabi, B. (2009). Knowledge Management and Learning Organization: Analyzing the Role of Knowledge and Experience Documentation, Journal of Information Technology Management, 1: 3-18

Shami Zanjani, M. (2009). Identification of factors influencing knowledge in management of projects. PhD Thesis, School of Management, Tehran University.

Martin J. Organizational Culture, mapping the terrain. California: Sage Publication.2011.

Elsey B, Eskandari M. Identifying the management development needs of senior executives in Iran's teaching hospitals. J Manag Med 1999; 13(6): 421-35. 